\title{
Endovascular treatment of PA pseudoaneurysm caused by Swan-Ganz catheter
}

\author{
Piotr N. Rudziński ${ }^{1}$, Marcin Demkow¹, llona Michałowska², Elżbieta Abramczuk³, Piotr Szymański \\ ${ }^{1}$ Department of Coronary and Structural Heart Diseases, Institute Cardiology, Warsaw, Poland \\ ${ }^{2}$ Department of Radiology, Institute Cardiology, Warsaw, Poland \\ ${ }^{3}$ Department of Acquired Cardiac Defects, Institute Cardiology, Warsaw, Poland
}

Postep Kardiol Inter 2014; 10, 1 (35): 66-70

DOI: 10.5114/pwki.2014.41476

\begin{abstract}
A bstract
The following case report describes a complication of Swan-Ganz catheterization and its endovascular treatment with a single coil. Application of this particular catheter in the pulmonary artery during cardiac surgery may lead to mechanical perforation and creation of an extravascular sac, which is called a pseudoaneurysm. There are different methods that lead to tamponade or closure of the leakage. Interventional cardiology procedures are nowadays the most appropriate way of treatment of Swan-Ganz catheter induced vascular complications.
\end{abstract}

Key words: pulmonary pseudoaneurysm, Swan-Ganz catheter, pulmonary artery, transcatheter embolization.

\section{Introduction}

Application of a Swan-Ganz catheter in the pulmonary artery may lead to mechanical complications, including artery perforation and life-threatening lung pseudoaneurysm formation [1]. The following case report describes this problem and its endovascular treatment with a single coil.

\section{Case report}

A 55-year-old deaf patient was admitted for surgical treatment of his severe bicuspid aortic valve stenosis. Surgical intervention was performed on the $18^{\text {th }}$ of September 2012. A mechanical aortic bicuspid valve (SJM Regent ${ }^{\circledR}$ Valve, diameter of $25 \mathrm{~mm}$ ) was implanted. After surgery, the patient reported fever and hemoptysis. Antibiotic therapy and a temporary discontinuation of oral anticoagulation was prescribed, which reduced inflammatory parameters and stopped the hemoptysis.

On the $25^{\text {th }}$ of September 2012, control chest radiography (Figure 1) showed atelectasis or inflammation of rear base segments of the right lung. Additionally, the presence of small quantities of fluid in both pleural cavities was revealed.

On the $2^{\text {nd }}$ of October 2012 chest radiography was performed again (Figure 2). Unlike in the previous study, at the place of previously described parenchymal densities, a circular shadow with a diameter of $26 \mathrm{~mm}$ was observed. Finally, computed tomography revealed a pseudoaneurysm of the right inferior lobe supplied by a subsegmental artery (Figure 3).

The patient was classified for transcatheter embolization of the pseudoaneurysm feeding artery. The procedure was performed on the $15^{\text {th }}$ of October 2012 from a femoral venous approach. The subsegmental pulmonary artery branch was cannulated with a Cournand type $6 \mathrm{Fr}$ catheter (Figure 4). Selective hand contrast injection showed the ruptured artery actively bleeding into the pseudoaneurysm. A single 4 loop, $3 \mathrm{~mm}$ diameter coil (M Reye ${ }^{\circledast}$ Flipper $^{\circledast}$ PDA Closure Detachable Coil, IMWCE3-PDA-4, William Cook Europe) was implanted just above the artery rupture point and below the last bifurcation. The angiogram $5 \mathrm{~min}$ after the implantation showed complete closure of the feeding artery (Figure 5). Further hospitalization was uneventful.

On the $19^{\text {th }}$ of October 2012, control postoperative chest radiography showed the vascular coil in position (Figure 6). The oval shadow size was reduced and exhibited consolidation. Other details of the radiography remained unchanged.

\section{Corresponding author:}

Piotr N. Rudziński MD, Department of Coronary and Structural Heart Diseases, Institute Cardiology, 42 Alpejska St, 04-628 Warsaw, Poland, phone: +48 608499 737, e-mail: piotr.rudzinski@ikard.pl

Received: 18.12.2013, accepted: 9.01.2014. 

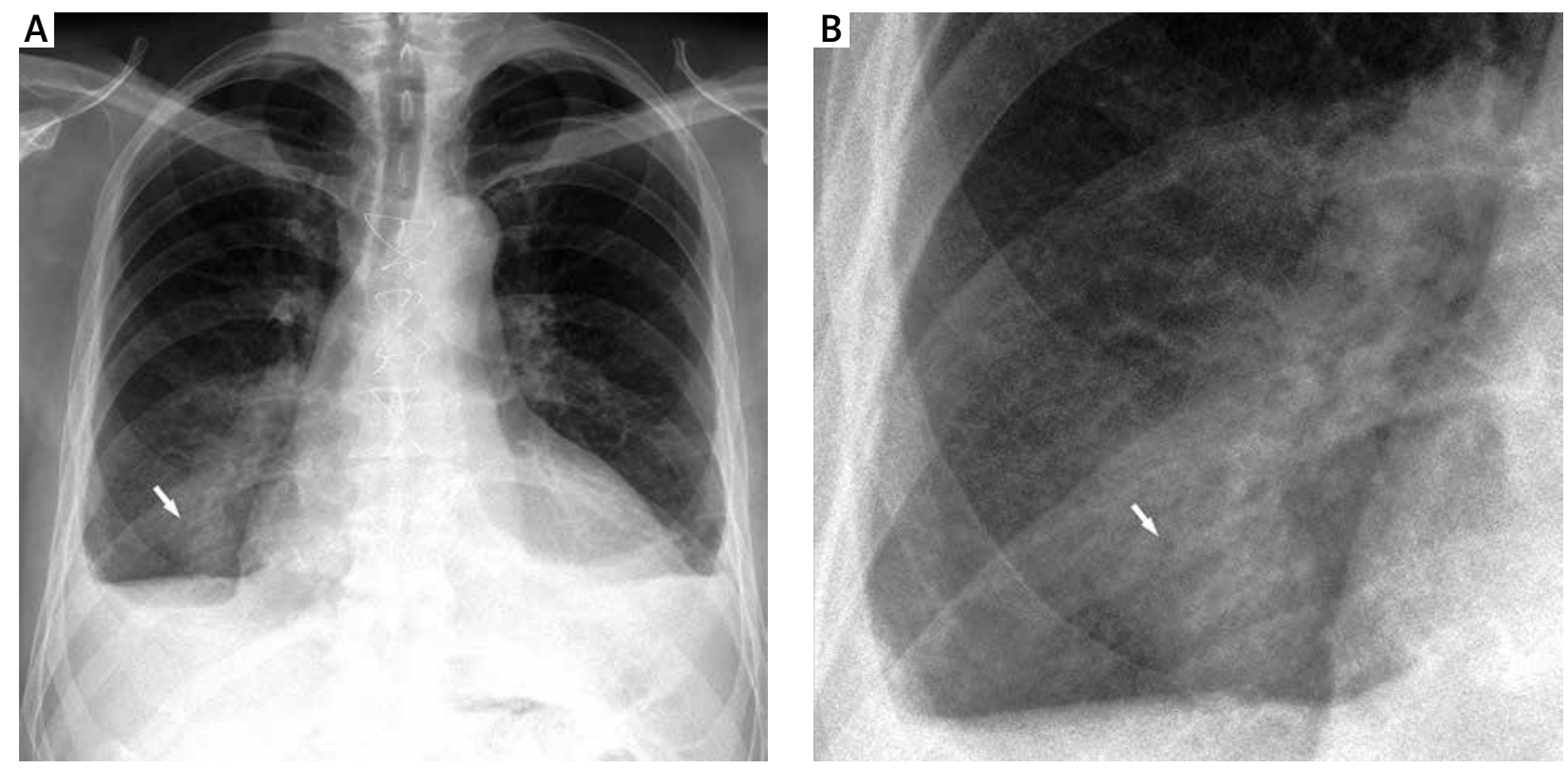

Figure 1. Chest radiogram from 25.09.2012 (A-P position). Suspected changes imitating atelectasis or inflammation of rear base segments of the right lung (white arrows)
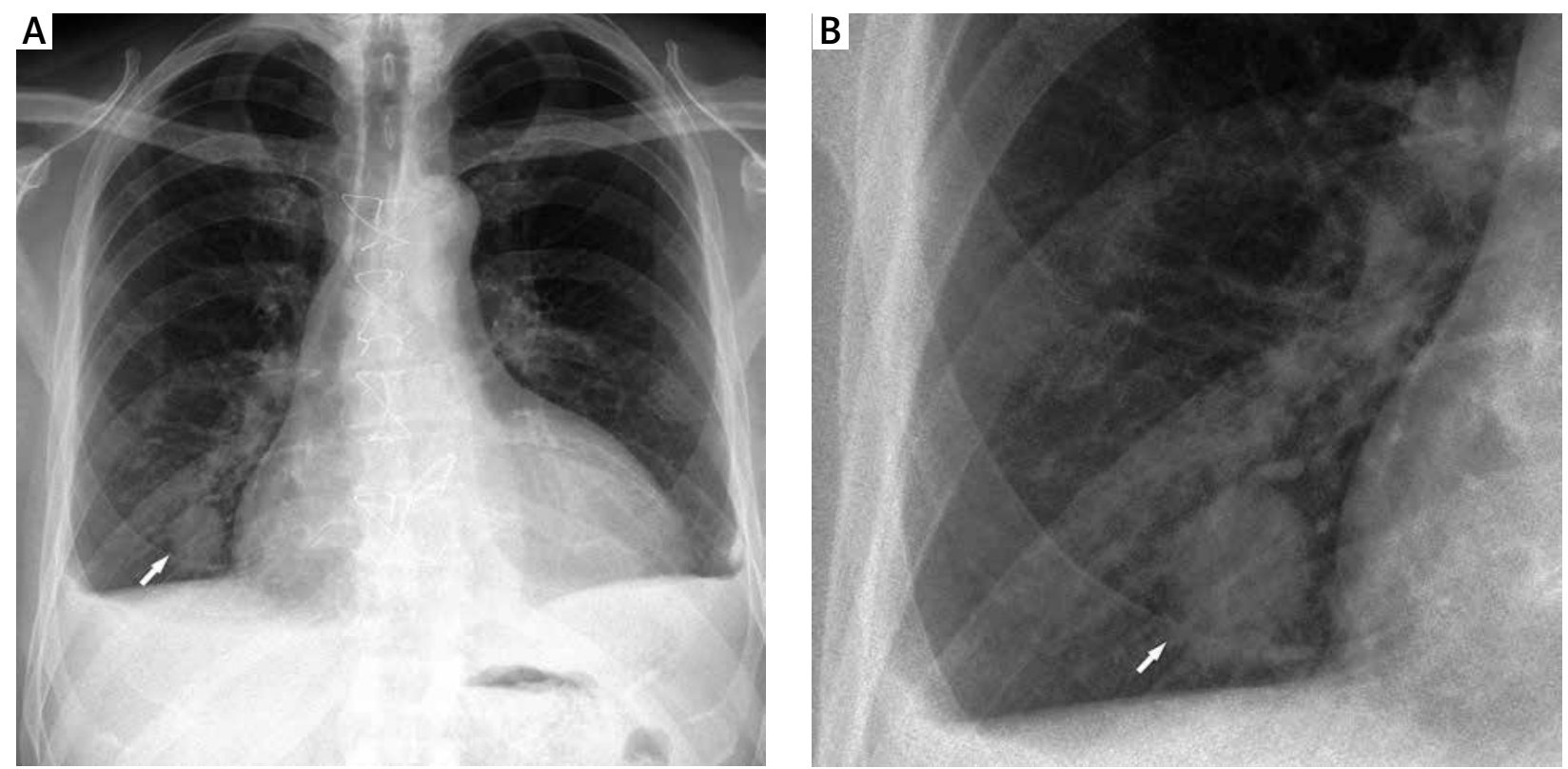

Figure 2. Chest radiogram from 02.10.2012 (A-P position). Circular shadow with a diameter of $26 \mathrm{~mm}$ is present in the place of previously described parenchymal changes (white arrows)

\section{Discussion}

The placement of a Swan-Ganz catheter into a pulmonary artery can cause different complications (2-17\%) [2], such as: arrhythmias, pneumothorax, heart block, lung infarction, perforation of the balloon, thrombosis, air embolism, knotting of the catheter, valvular damage, or infection [3-5].

Rupture of the pulmonary artery due to Swan-Ganz catheter application is one of the infrequent side effects
$(0.016-0.2 \%)$ [1]. At the same time, it belongs to the most serious and the most dynamic group of complications [6-12], causing high mortality (in approximately $50 \%$ of cases) $[10,13]$. The right lung is affected in $90 \%$ of reports, usually the right lower lobe [14].

The symptoms can vary from slight cough (low hemoptysis) even to massive hemorrhage. In each of these conditions, a pseudoaneurysm in the lung tissues can be formed. There are cases in which pulmonary artery perfo- 


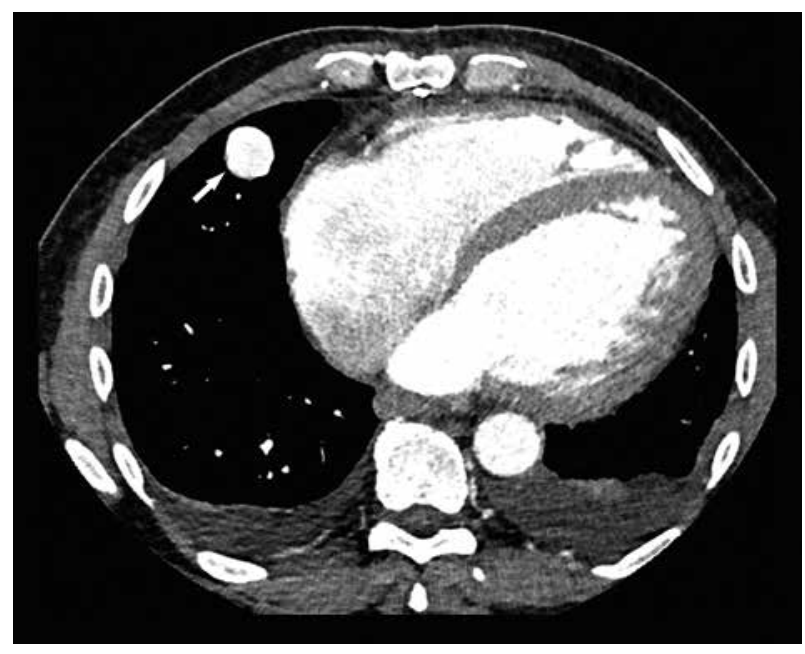

Figure 3. Transverse section of chest computed tomography confirms the presence of pseudoaneurysm in the right lung (white arrow)

ration is asymptomatic and is revealed only accidentally during the autopsy [15]. Multislice computed tomography can localize directly the affected vessel as well as the particular place of pseudoaneurysm formation. Furthermore, it is considered to be more accurate than pulmonary angiography (diagnostic gold standard) $[9,10]$.

In 1994, a review article published in the "Journal of Cardiothoracic and Vascular Anesthesia" contained 92 cases of perforation of the pulmonary artery caused by a pulmonary catheter. Among these cases, 28 led to formation of a pseudoaneurysm. Fourteen patients survived (11 were treated with embolization, 3 surgically), 13 pa- tients died (7 because of early rupture of the formed pseudoaneurysm, 6 because of other health complications), and 1 patient was not reported. Moreover, it was proven that a pseudoaneurysm can be formed immediately, as well as during 7 months after the injury $[16,17]$.

Mechanical complications of Swan-Ganz catheter application can be treated surgically (reconstruction of pulmonary artery, lobectomy, lung resection) [12] or endovascularly (embolization) [3, 18, 19]. Endovascular therapy is a safe, quick and low cost alternative to surgical techniques [20]. Despite this fact, it is important to emphasize that even though pulmonectomy increases mortality, sometimes in severe cases it is the only way of treatment [21]. Means of interventional cardiology comprise methods such as transcatheter detachable balloon technique [22, 23], or insertion of a specific coil (therapeutic gold standard) $[6,10,13,23,24]$. Moreover, use of an Amplatzer ${ }^{\circledast}$ Vascular Plug has recently been described [14]. One of the patterns consists even of a local thrombin injection using the distal port of the Swan-Ganz catheter. This method might be accompanied by balloon inflation, which can act as a temporary tamponade preventing formation and enlargement of the pseudoaneurysm [25]. Considering other methods, there is a case report which reveals that extracorporeal membrane oxygenation (ECMO) can reduce bleeding from the ruptured pulmonary artery caused by the Swan-Ganz catheter. Extracorporeal membrane oxygenation was applied in order to improve blood oxygenation and severe hypoxemia and, in consequence, to achieve clinical stability more rapidly [24]. What is more, others concluded that in the absence of particular risk factors (such as pulmonary hyperten-
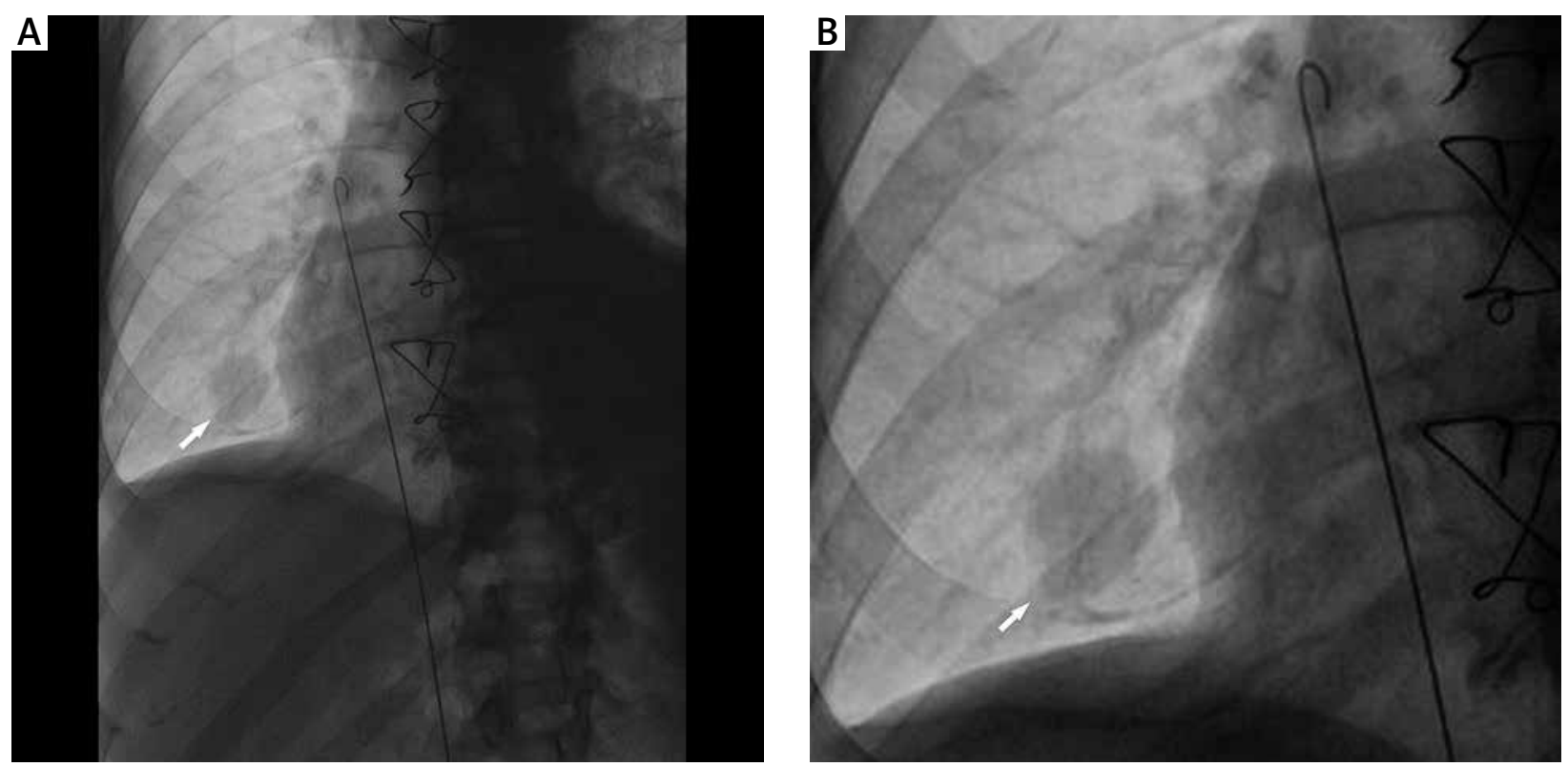

Figure 4. Introduction of catheter via right femoral vein. Fluoroscopy of chest shows again the location of round mass corresponding to pseudoaneurysm (white arrows) 

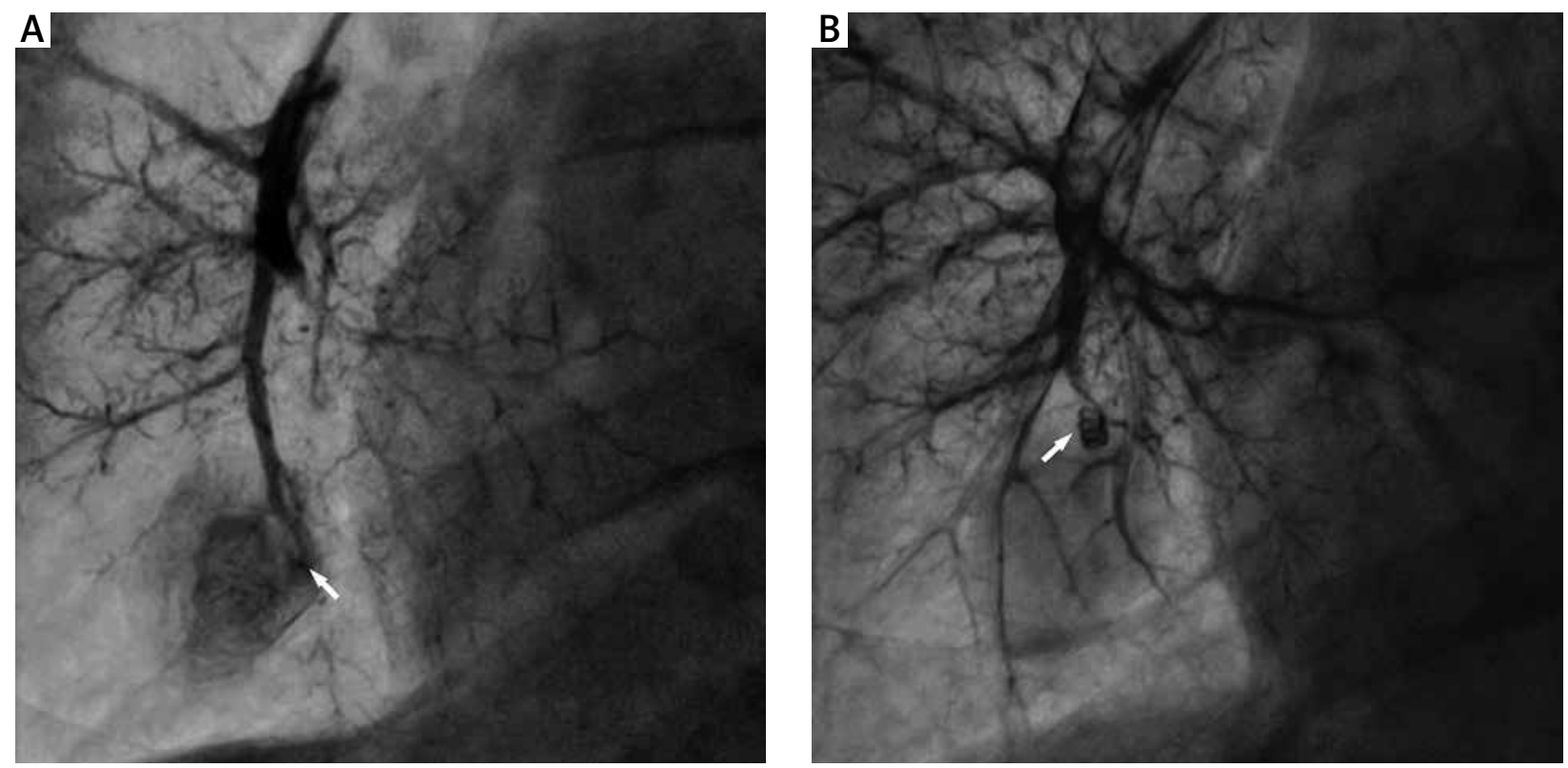

Figure 5. A - Dye injection shows pulmonary artery rupture and arterial blood leakage (white arrow) with creation of pseudoaneurysm. B - The metal coil (white arrow) is formed in the perforated artery occluding the feeding artery
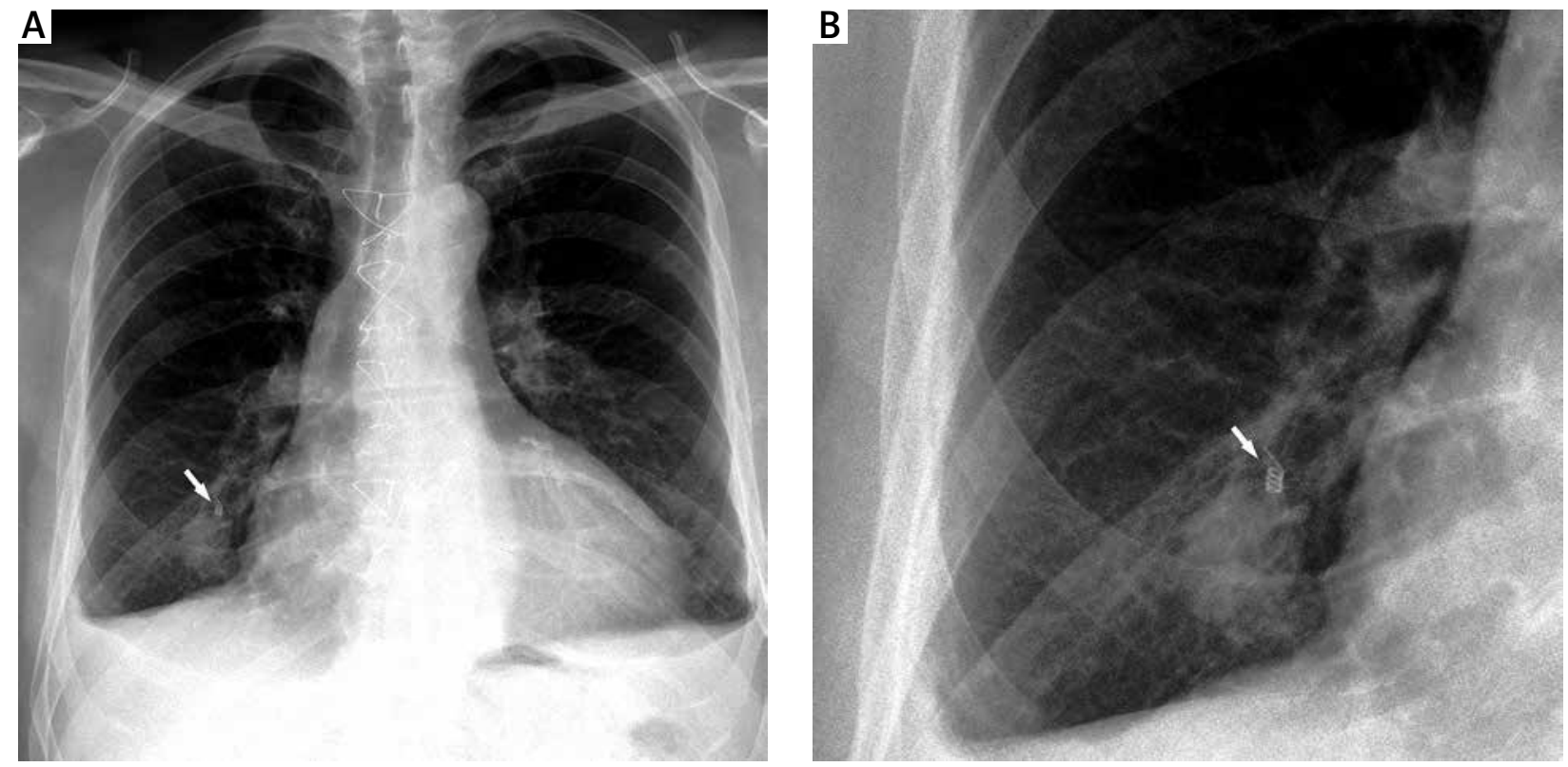

Figure 6. Chest radiogram from 19.10.2012 (A-P position) shows allocation of the metal coil (white arrow) and slight size reduction of the pseudoaneurysm

sion and use of systemic anticoagulants) the treatment of pulmonary artery rupture can consist only of supportive care [1].

\section{Conclusions}

Even though iatrogenic perforation of the pulmonary artery caused by a Swan-Ganz catheter is infrequent, it is still a life-threatening condition that should be recog- nized and cured immediately. Among all treatment patterns, means of endovascular cardiology are relatively quick, accurate and highly effective. They act as an alternative to very traumatizing surgical treatment. Moreover, interventional cardiology permanently develops by searching for innovations, modern techniques and new implantable devices, as well as for new applications for already well-known equipment. 


\section{References}

1. Stancofski ED, Sardi A, Conaway GL. Successful outcome in SwanGanz catheter-induced rupture of pulmonary artery. Am Surg 1998; 64: 1062-1065.

2. Labrunie E, Levy C, Paugam C, et al. Pulmonary artery pseudoaneurysm caused by a Swan-Ganz catheter and treated by embolization. Ann Radiol (Paris) 1993; 36: 310-314.

3. Bossert T, Gummert JF, Bittner HB, et al. Swan-Ganz catheter induced severe complications in cardiac surgery: right ventricular perforation, knotting, and rupture of a pulmonary artery. J Card Surg 2006; 21: 292-295.

4. Troianos CA, Stypula RW. Transesophageal echocardiographic diagnosis of pulmonary artery catheter entrapment and coiling. Anesthesiology 1993; 79: 602-604.

5. Feng WC, Singh AK, Drew T. Swan-Ganz catheter-induced massive hemoptysis and pulmonary artery false aneurysm. Ann Thorac Surg 1990; 50: 644-646.

6. Poplausky MR, Rozenblit G, Rundback JH, et al. Swan-Ganz catheter-induced pulmonary artery pseudoaneurysm formation: three case reports and a review of the literature. Chest 2001; 120: 21052111.

7. Bhatia P, Saied NN, Comunale ME. Management of an unusual complication during placement of a pulmonary artery catheter. Anesth Analg 2004; 99: 669-671.

8. Settergen G, Angdin M, Anderson RE, et al. Wedging the pulmonary artery catheter: changes in left atrial and pulmonary artery pressures and risk for performation. J Cardiothorac Vasc Anesth 2006; 20: 311-314.

9. Kierse R, Jensen $\mathrm{U}$, Helmberger $\mathrm{H}$, et al. Value of multislice $\mathrm{CT}$ in the diagnosis of pulmonary artery pseudoaneurysm from SwanGanz catheter placement. J Vasc Interv Radiol 2004; 15: 1133-1137.

10. Abreu AR, Campos MA, Krieger BP. Pulmonary artery rupture induced by a pulmonary artery catheter: a case report and review of the literature. J Intensive Care Med 2004; 19: 291-296.

11. Utsumi T, Kido T, Ohata T, et al. Swan-Ganz catheter-induced pseudoaneurysm of the pulmonary artery. Jpn J Thorac Cardiovasc Surg 2002; 50: 347-349.

12. Deren MM, Barash PG, Hammond GL, et al. Perforation of the pulmonary artery requiring pneumonectomy after the use of a flow-directed (Swan-Ganz) catheter. Thorax 1979; 34: 550-553.

13. Gottwalles Y, Wunschel-Joseph ME, Hanssen M. Coil embolization treatment in pulmonary artery branch rupture during Swan-Ganz catheterization. Cardiovasc Intervent Radiol 2000; 23: 477-479.

14. Kalra A, Heitner S, Topalian S. Iatrogenic pulmonary artery rupture during Swan-Ganz catheter placement - a novel therapeutic approach. Catheter Cardiovasc Interv 2013; 81: 57-59.

15. Bussi res JS. latrogenic pulmonary artery rupture. Curr Opin Anaesthesiol 2007; 20: 48-52.

16. DeLima LG, Wynands JE, Bourke ME. Catheter-induced pulmonary artery false aneurysm and rupture: case report and review. J Cardiothorac Vasc Anesth 1994; 8: 70-75.

17. You CK, Whatley GS. Swan-Ganz catheter-induced pulmonary pseudoaneurysm: a case of complete resolution without intervention. Can J Surg 1994; 37: 420-424.

18. Finfer S, Delaney A. Pulmonary artery catheters. BMJ 2006; 333: 930-931.

19. Urschel JD, Myerowitz PD. Catheter-induced pulmonary artery rupture in the setting of cardiopulmonary bypass. Ann Thorac Surg 1993; 56: 585-589.
20. Karak P, Dimick R, Hamrick KM, et al. Immediate transcatheter embolization of Swan-Ganz catheter-induced pulmonary artery pseudoaneurysm. Chest 1997; 111: 1450-1452.

21. Mullerworth MH, Angelopoulos P, Couyant MA, et al. Recognition and management of catheter-induced pulmonary artery rupture. Ann Thorac Surg 1998; 66: 1242-1245.

22. Brahim JJ, Cheung D, Jessurun JA, et al. Rounded mass in the middle lobe after Swan-Ganz catheterization. Chest 2002; 121: 261-263.

23. Cooper JP, Jackson J, Walker JM. False aneurysm of the pulmonary artery associated with cardiac catheterisation. Br Heart J 1993; 69: 188-190.

24. Bianchini R, Melina G, Benedetto U, et al. Extracorporeal membrane oxygenation for Swan-Ganz induced intraoperative hemorrhage. Ann Thorac Surg 2007; 83: 2213-2214.

25. Dobies DR, Cohoon AL, Bates AA. Images in cardiovascular medicine. Repair of a perforated pulmonary artery due to a SwanGanz catheter using thrombin injection. Circulation 2009; 119: 521-522. 